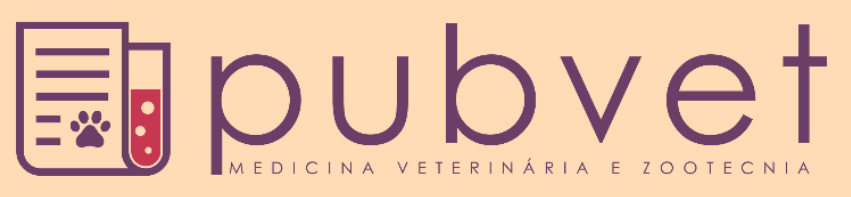

https://doi.org/10.31533/pubvet.v12n12a234.1-4

\title{
Brucelose bovina: situação epidemiológica em rebanhos do município de Codó-MA
}

\author{
Oswaldo Palma Lopes Sobrinho ${ }^{1 * \bullet}$, Glayde Maria Carvalho Véras ${ }^{2} \bullet$, Lana Fernanda Borges da \\ Silva $^{2}$, Luciana dos Santos Oliveira ${ }^{2}$, Rosinete dos Santos Xavier ${ }^{2}{ }^{\ominus}$, Jorgeana Francis \\ Alvim $^{2} \theta$, Denise Arrais da Silva $\operatorname{Costa}^{2} \theta$, Álvaro Itaúna Schalcher Pereira ${ }^{2} \theta$, Maria da Assunção \\ Silva $\operatorname{Carlos}^{20}$, Erika de Kássia Pereira Cantanhede ${ }^{2}$, Maria de Lurdes Campos dos Santos ${ }^{30}$ \\ ${ }^{1}$ Engenheiro Agrônomo Instituto Federal de Educação, Ciência e Tecnologia do Maranhão (IFMA)-Campus Codó (IFMA). Mestrando em \\ Ciências Agrárias - Agronomia pelo Instituto Federal de Educação, Ciência e Tecnologia Goiano - Campus Rio Verde, Goiás, Brasil. \\ ${ }^{2}$ Departamento de Ensino, Instituto Federal de Educação, Ciência e Tecnologia do Maranhão (IFMA), Codó, Maranhão, Brasil. \\ ${ }^{3}$ Engenheira Agrônoma pelo IFMA-Campus Codó (IFMA). Mestranda em Solos e Qualidade de Ecossistemas pela Universidade Federal do \\ Recôncavo da Bahia (UFRB), Cruz das Almas, Bahia, Brasil. \\ *Autor para correspondência, E-mail: oswaldo-palma@hotmail.com
}

RESUMO. A brucelose é uma doença infecciosa, provocada por bactérias do gênero Brucella abortus. Essa doença pode causar perda da libido e infertilidade nos machos, abortos e endometrites em fêmeas. Este trabalho descreve a situação epidemiológica da brucelose bovina no município de Codó-MA. O estudo compreendeu um delineamento qualitativo do tipo levantamento epidemiológico e os dados foram coletados junto à Agência de Defesa Agropecuária do Estado do Maranhão (AGED-Codó), através de boletins mensais emitidos por médicos veterinários para o período de maio de 2010 a março de 2012. Constatou-se que de 5.283 animais existentes em rebanhos, a maioria não foram vacinados, com percentual de $80 \%$ e apenas $20 \%$ comprovaram a vacinação. Ademais com esta situação epidemiológica preocupante da brucelose se faz necessário desenvolver trabalhos referentes à sensibilização dos pecuaristas em relação à gravidade desta zoonose e uma forte campanha de erradicação. $\mathrm{O}$ aumento da incidência dessa doença acarreta graves problemas de perdas econômicas à pecuária local.

Palavras chave: Bovinocultura, abortos, pecuária local

\section{Bovine brucellosis: epidemiological situation in herds of the municipality of Codó-MA}

\begin{abstract}
Brucellosis is an infectious disease caused by bacteria of the genus Brucella abortus. This disease can cause loss of libido and infertility in males, abortions and endometrites in females. This paper describes the epidemiological situation of bovine brucellosis in the municipality of Codó-MA. The study comprised a qualitative epidemiological survey design and the data were collected from the Agricultural Defense Agency of the State of Maranhão (AGED-Codó), through monthly bulletins issued by veterinarians from may 2010 to march 2012. It was verified that of 5,283 animals in herds, the majority were not vaccinated, with $80 \%$ percentage and only $20 \%$ verified the vaccination. In addition to this epidemiological situation worrisome of brucellosis, it is necessary to develop studies regarding the sensitization of cattle farmers in relation to the severity of this zoonosis and a strong eradication campaign. The increase in the incidence of this disease causes serious problems of economic losses to the local cattle ranch.
\end{abstract}

Keywords: Cattle breeding, abortion, local livestock 


\title{
Brucelosis bovina: situación epidemiológica en rebaños del municipio de Codó-MA
}

\begin{abstract}
RESUMEN. La brucelosis es una enfermedad infecciosa, provocada por bacterias del género Brucella abortus. Esta enfermedad puede causar pérdida de la libido e infertilidad en los machos, los abortos y los endometrios en las hembras. Este trabajo describe la situación epidemiológica de la brucelosis bovina en el municipio de Codó-MA. El estudio comprendió un delineamiento cualitativo del tipo levantamiento epidemiológico y los datos fueron recolectados junto a la Agencia de Defensa Agropecuaria del Estado de Maranhão (AGED-Codó), a través de boletines mensuales emitidos por médicos veterinarios para el período de mayo de 2010 a marzo de 2012. Se constató que de 5.283 animales existentes en rebaños, la mayoría no fueron vacunados, con un porcentaje del $80 \%$ y sólo el $20 \%$ comprobaron la vacunación. Además con esta situación epidemiológica preocupante de la brucelosis se hace necesario desarrollar trabajos referentes a la sensibilización de los ganaderos en relación a la gravedad de esta zoonosis y una fuerte campaña de erradicación. El aumento de la incidencia de esta enfermedad acarrea graves problemas de pérdidas económicas a la ganadería local.
\end{abstract}

Palabras clave: Bovinocultura, abortos, ganadería local

\section{Introdução}

A brucelose bovina é uma enfermidade infectocontagiosa de caráter crônico e zoonótico, causada por bactérias do gênero Brucella abortus (Walker 2003). Conforme Brasil (2006) a Brucella abortus é apresentada de forma endêmica em muitos países, resultando em prejuízos econômicos significativos aos sistemas de produção e sérias implicações na saúde animal e pública.

A sua ocorrência num país e/ou determinada região pode ocasionar perdas econômicas, tais como: a imposição de barreiras sanitárias e tarifárias ao comércio internacional de produtos de origem animal, provocar perdas no rendimento industrial com a condenação do leite e da carne provenientes de animais infectados, bem como o elevado número de abortos, nascimento de bezerros fracos, baixa fertilidade nas propriedades rurais e, principalmente o declínio na produção de leite e carne (Poester et al. 2009).

A transmissão desta zoonose entre rebanhos estão relacionados à aquisição de animais infectados, proximidade a rebanhos infectados, que compartilham pastagem e água, e animais que se alimentam de outros em decomposição. Dentro do rebanho, a transmissão da enfermidade é influenciada pelo nível 1 de vacinação, tamanho do rebanho, condições de instalações, uso de piquetes maternidade e densidade populacional (Crawford et al. 1990). A vacinação de animais geralmente resulta na eliminação do principal quadro clínico da brucelose, que é o aborto, e na redução do número de micro-organismos excretados por animais infectados (Corbel 2006). Sendo assim, a vacinação promove uma diminuição da prevalência e da incidência da doença, propiciando um avanço do programa de controle em direção à erradicação da doença (Lage et al. 2005; Olsen \& Stoffregen 2005).

A escassez de estudos sobre brucelose para a região dos cocais maranhenses e levando em consideração os prejuízos que essa doença pode ocasionar a pecuária local e saúde pública, justifica-se este trabalho, que teve por objetivo descrever a situação epidemiológica da brucelose bovina no município de Codó-MA.

\section{Material e métodos}

O estudo compreendeu um delineamento qualitativo do tipo levantamento epidemiológico acerca da brucelose em rebanhos de espécie bovina no município de Codó-MA. Os dados foram coletados junto à Agência de Defesa Agropecuária do Estado do Maranhão (AGED/Codó) por meio de boletins mensais de brucelose emitidos por médicos veterinários que atuam na região dos cocais maranhenses para $o$ período de maio de 2010 a março de 2012.

Algumas informações foram coletadas tais como: à vacinação dos bovinos, número de propriedades e fêmeas afetadas, às medidas adotadas para abortos e no momento do parto, à frequência de realização de diagnósticos visando determinar os fatores predisponentes para a enfermidade na região. 
A economia do município de Codó-MA é caracteriza pela forte intervenção de atividades agropecuárias, onde predomina a agricultura de subsistência, além da pecuária voltada a pequenos e médios produtores de leite.

Para caracterização da importância dos fatores de riscos na transmissão da doença entre os animais fez-se um levantamento epidemiológico através do histórico de criadores e foi registrado casos de abortos, retenções de placentas, esterilidade e informações sanitárias.

\section{Resultados e discussão}

De acordo com os dados fornecidos por médicos veterinários, no período de maio de 2010 a março de 2012, existem 581 propriedades cadastradas, nos quais estas foram notificadas da necessidade da vacinação de bezerras de 3 a 8 meses. Constatou-se que de 5.283 animais existentes em rebanhos, a maioria não foram vacinados com percentual de $80 \%$ e apenas $20 \%$ comprovaram a vacinação.

Tabela 1. Quantidades de fêmeas que foram ou não vacinadas contra a brucelose e propriedades rurais no período de maio de 2010 a março de 2012, no município de Codó-MA, Brasil.

\begin{tabular}{lcc}
\hline Vacinação das fêmeas & $\begin{array}{c}\text { Número de } \\
\text { propriedades }\end{array}$ & Propriedades, \% \\
\hline Comprovam à vacinação & 196 & 34 \\
Não comprovamà vacinação & 385 & 66 \\
\hline & No de bezerras $^{\circ}$ & Bezerras, \% \\
\hline Vacinadas & 1.064 & 20 \\
Não vacinadas & 4.219 & 80 \\
\hline
\end{tabular}

Observou-se que $34 \%$ das propriedades comprovaram à vacinação contra a enfermidade brucelose, percentual esse considerado insuficiente em relação à quantidade de fêmeas em idade de vacinação na região e $66 \%$ mostraram atitudes contrárias. Assim sendo, este percentual é considerado significativo e preocupante, uma vez que, a enfermidade é responsável por ocasionar transtornos reprodutivos e consequentes perdas econômicas à pecuária local. Além disso, representa riscos à saúde pública, principalmente para aqueles que trabalham diretamente com os animais. Tal situação pode ser explicada pela falta da não vacinação e precárias condições sanitárias do manejo nas propriedades estudadas. Os criadores demonstraram total desinformação quanto à importância e à idade da vacinação e as realizavam na época do desmame. Dessa forma, a idade de desmame pode variar de 10 meses a 1 ano e 6 meses.
Constatou-se a aplicação de forma inadequada da vacinação e que os produtores não adotam medidas preventivas e/ou mitigadoras de destinos adequados aos restos de abortos e partos na propriedade. A idade máxima indicada para imunização de animais é de 8 meses de idade (Nicoletti 1990). Em relação aos dados sobre o manejo sanitário dos rebanhos obtidos pelos boletins mensais fornecidos pela AGED/Codó, embora tenha sido baixa a frequência de vacinação, há uma grande movimentação e campanha na realização de exames sobre a brucelose.

Com base nos dados obtidos, percebeu-se que o município de Codó-MA tem a classificação de $0 \%$ de casos com a brucelose na espécie bovina, podendo ser enquadrada como integrante da zona de baixo risco, uma vez que, a infecção de rebanho apresentou-se abaixo de $10 \%$ e a de animais menos que $3 \%$. Utilizou-se por base a classificação apresentada pelo documento para análise estatísticoepidemiológico desenvolvido pela Companhia Integrada de Desenvolvimento Agrícola de Santa Catarina - CIDASC (Cidasc 2000).

Nos rebanhos algumas características podem facilitar a transmissão da brucelose, tais como: a maior frequência de reposição de animais, número de problemas relacionados ao controle sanitário e à influência na dinâmica da doença (Crawford et al. 1990). Assim sendo, o número elevado de animais com ocorrência no rebanho constitui maior risco de introdução e disseminação da brucelose.

A associação de nascimento de bezerros fracos em condições de foco da brucelose bovina foram descrevidos por vários autores (Nicoletti 1986; Samartino \& Enright 1993). Em animais brucélicos, um acontecimento constante na primeira gestação é o aborto. Entretanto, o comum em gestações subsequentes, é o nascimento de animais fracos, devido ao menor número de placentomas e grau de lesão observado. Portanto, a diminuição da passagem de nutrientes e oxigênio não chega a causar a morte, mas compromete o desenvolvimento do feto, ocasionando o nascimento de animais pequenos e subdesenvolvidos (Pellegrin et al. 2006). Assim sendo, a ocorrência de nascimento de bezerros fracos é uma consequência da brucelose.

É necessária uma forte campanha de erradicação da brucelose, uma vez que, o número de bezerras não vacinadas nas propriedades existentes corresponde a $80 \%$ tonando-se uma situação preocupante. Diante disso, o Programa Nacional de Controle e Erradicação da Brucelose (PNCEB) surge como estratégia de ação estando relacionado à certificação 
de propriedades livres e/ou monitoradas, de adesão voluntária. Além disso, é um instrumento em que os produtores e o setor agroindustrial podem utilizar para agregar valores aos seus produtos e subprodutos.

São preconizadas medidas sanitárias compulsórias de eficácia comprovada, como a vacinação de bezerras contra a brucelose e o controle do trânsito de animais destinados à reprodução, visando baixar a prevalência e incidência de casos e níveis compatíveis com ações sanitárias mais drásticas, que caracterizam um programa de erradicação.

$\mathrm{O}$ controle da brucelose é fundamentado em ações de vacinação de fêmeas de 3 a 8 meses, diagnóstico e sacrifício dos animais positivos. Os programas de desinfecção e utilização de piquetes de parição são iniciativas simples que trazem como resultado a diminuição da quantidade de brucelas vivas presentes no ambiente. Isso representa diminuir a dose de desafio, o que, por sua vez, significa aumentar os índices de proteção da vacina e diminuir a chance de a bactéria infectar um novo suscetível (Brasil, 2006).

\section{Conclusões}

Ademais a situação epidemiológica encontrada da brucelose em rebanhos bovinos no município de CodóMA torna-se preocupante, sendo necessário desenvolver pesquisas referentes à sensibilização dos pecuaristas em relação à gravidade desta zoonose e uma campanha eficiente voltada à erradicação. Pois o aumento da incidência dessa doença acarreta graves problemas de perdas econômicas à região. Todavia, é necessário despertar aos criadores à importância de erradicar não apenas a brucelose, mas também outras enfermidades, como por exemplo, a febre aftosa, dentre outras que tanto trazem prejuízos à pecuária local e de âmbito estadual, quanto às preocupações com a saúde pública municipal. Destarte, se fazem necessários a (re) implantação de políticas públicas com ações direcionadas para o manejo sanitário de criadores de bovinos, levando em consideração à vacinação regular dos rebanhos, monitoramento constante das propriedades e, principalmente àquelas que se encontra com maiores condições de riscos.

\section{Referências Bibliográficas}

Brasil 2006. Ministério da Agricultura, Pecuária e Abastecimento. Manual Técnico: Programa Nacional de Controle e Erradicação de Brucelose e Tuberculose Animal - PNCEBT, Brasília, 84p.
Cidasc 2000.Testes da Brucelose Realizados pela Regional de Lages. Lages, SC. (ed. by Gerência Estadual de PecuáriaFlorianópolis S). Unidade Local de Saúde Animal e Vegetal. Lages, Florianópolis, Santa Catarina, Brasil.

Corbel M.J. 2006. Brucellosis in man and animals. 2006, Geneva, Suiça.

Crawford R.P., Huber J.D. \& Adams B.S. 1990. Epidemiology and surveillance. In: Animal brucellosis (eds. by Nielsen K \& Duncan JR), pp. 131-151. Boca Raton: CRC Press.

Lage A.P., Poester F.P. \& Gonçalves V.S.P. 2005. Controle da brucelose bovina. Cadernos Técnicos de Veterinária e Zootecnia 47, 30-41.

Nicoletti P. 1986. Effects of brucellosis on bovine reproductive efficiency. In: Current therapy in theriogenology (ed. by Morrow DA), pp. 271-274.

Nicoletti P. 1990. Vaccination. In: Animal Brucellosis (eds. by Nielsen KH \& Duncan JR), pp. 283-300. Boca Raton: CRC.

Olsen S.C. \& Stoffregen W.S. 2005. Essential role of vaccines in brucellosis control and eradication programs for livestock. Expert review of vaccines 4, 915-928.

Pellegrin A.O., Leite R., Sereno J.R.B., Lage A.P., Leite R.C. \& Ravaglia E. 2006. Brucelose bovina no Pantanal Sul-Matogrossense: dados preliminares. Embrapa Pantanal-Comunicado Técnico 58, 1-4.

Poester F., Figueiredo V.C.F., Lôbo J.R., Gonçalves V.S.P., Lage A.P., Roxo E., Mota P.M.P.C., Müller E.E. \& Ferreira Neto J.S. 2009. Estudos de prevalência da brucelose bovina no âmbito do Programa Nacional de Controle e Erradicação de Brucelose e Tuberculose: Introdução. Arquivo Brasileiro de Medicina Veterinária e Zootecnia 61, 1-5.

Samartino L.E. \& Enright F.M. 1993. Pathogenesis of abortion of bovine brucellosis. Comparative immunology, microbiology and infectious diseases 16, 95-101.

Walker L. 2003. Brucella. In: Microbiologia Veterinária (eds. by Hirsh DC \& Zee YC), pp. 185-191. Guanabara Koogan, Rio de Janeiro, Brasil.

Recebido: 23 outubro, 2018

Aprovado: 12 novembro, 2018.

Publicado: 26 dezembro, 2018.

Licenciamento: Este artigo é publicado na modalidade Acesso Aberto sob a licença Creative Commons Atribuição 4.0 (CC-BY 4.0), a qual permite uso irrestrito, distribuição, reprodução em qualquer meio, desde que o autor e a fonte sejam devidamente creditados. 